\title{
Controle de ácaros em sistema de produção integrada de morango
}

\author{
Control of mites in strawberry integrated production system
}

\author{
Marcos Antonio Matiello Fadini ${ }^{1}$ Angelo Pallini ${ }^{2}$ Madelaine Venzon ${ }^{3}$
}

\section{- REVISÃO BIBLIOGRÁFICA -}

RESUMO

A produção integrada é um sistema agrícola que objetiva produzir alimentos de boa qualidade de acordo com os requerimentos de sustentabilidade ambiental, segurança alimentar e viabilidade econômica. Apesar de ainda não existirem projetos de produção integrada de morango, técnicas de controle biológico e de resposta induzida a herbivoria poderiam ser utilizadas no controle de ácaros fitófagos do morangueiro. Nesta revisão, serão discutidas estas técnicas de manejo de ácaros dentro do contexto da produção integrada de morango.

Palavras-chave: controle biológico, resposta induzida, Fragaria.

\section{ABSTRACT}

Integrated production is an agricultural system that aims to produce good quality food, in conformity with the requirements of ambient sustainability, alimentary security and economic viability. Although there is not yet a developed integrated system for strawberry production, techniques based on biological control and induced responses to herbivory could be used to control phytophagous mites on strawberry. In this review we discuss these techniques within an integrated production context on strawberry.

Key words: biological control, induced response, Fragaria.

\section{INTRODUÇÃO}

A atual demanda mundial por alimentos certificados e isentos de resíduos de pesticidas tem pressionado o modelo convencional agrícola a constantes reavaliações de seus métodos de produção. Modelos de produção baseados em altos gastos energéticos com pesticidas e fertilizantes estão sendo reavaliados quanto à sua sustentabilidade ao longo do tempo e a suas conseqüências ao homem e ao meio ambiente (FADINI \& LOUZADA, 2001). Esta tendência tecnológica tem sido impulsionada principalmente por pressão de grupos de consumidores esclarecidos quanto aos problemas ambientais decorrentes de práticas agrícolas convencionais. $\mathrm{O}$ consumidor tem, cada vez mais, interesse em conhecer como os alimentos são produzidos, se o modelo de produção agrícola utilizado está causando impactos danosos aos agroecossistemas e se existe algum risco de contaminação do alimento (PESSOA et al., 2002). A produção integrada, segundo TITI et al. (1995), é um "sistema de exploração agrária que objetiva produzir alimentos e outros produtos mediante o uso dos recursos naturais e de mecanismos reguladores para minimizar o uso de insumos e contaminantes e para assegurar uma produção agrária sustentável". Esse sistema de produção surgiu como uma extensão ao manejo integrado de pragas, cujos conhecimentos são estendidos a todo o sistema de produção de alimentos, e cujas práticas de manejo são realizadas de forma integrada, a fim de melhorar a qualidade dos alimentos e diminuir o uso de pesticidas (FACHINELLO, 2001). A produção integrada (PI)é um sistema que se situa entre a produção convencional e a produção orgânica, a qual, segundo FACHINELLO (2001) é considerada mais evoluída. Uma das principais diferenças entre esses dois sistemas, com relação ao controle de pragas, é que, na produção integrada, é permitido o uso de pesticidas, mas com

\footnotetext{
${ }^{1}$ Engenheiro Agrônomo, Doutorando, Pesquisador Empresa de Pesquisa Agropecuária do Estado de Minas Gerais (EPAMIG), Bolsista da Fundação de Amparo à Pesquisa do Estado de Minas Gerais (Fapemig), Departamento de Biologia Animal, Entomologia, Universidade Federal de Viçosa (UFV), 36571-000, Viçosa, MG. Email: fadini@insecta.ufv.br Autor para correspondência.

${ }^{2}$ Engenheiro Agrônomo, PhD, Professor, Bolsista do CNPq, Departamento de Biologia Animal, Entomologia, UFV.

${ }^{3}$ Engenheiro Agrônomo, PhD, Pesquisadora da EPAMIG, Bolsista do CNPq, Centro Tecnológico da Zona da Mata, EPAMIG, 36571-000, Viçosa, MG.
} 
restrições àqueles com impacto ambiental indesejável e/ou com potencial de eliminação de organismos benéficos (BRASIL, 2001), sendo que, na produção orgânica, os pesticidas não são permitidos (BRASIL, 1999). Assim, na PI o uso de técnicas que reduzem o uso dos pesticidas é fundamental para alcançar os objetivos propostos.

Ainda não existem iniciativas de adequarse um sistema de produção integrada do morangueiro (Fragaria x ananassa Duchesne) (ANTUNES \& FADINI, 2001), apesar de já existirem produtores cultivando o morangueiro em sistema orgânico.

Os problemas fitossanitários no morangueiro, assim como em outras olerícolas, são de difícil controle, necessitando constante controle. Este manejo é conseqüência de um mercado que exige um padrão de frutos livres de defeitos que somente é alcançado com um alto custo energético embutido nos insumos utilizados no controle.

Dentre os organismos daninhos associados à cultura do morangueiro, de acordo com HELLE \& SABELIS (1985), os ácaros fitófagos apresentam grande potencial de redução da produção devido principalmente ao alto potencial reprodutivo.

Assim, essa revisão objetiva apresentar as espécies de ácaros fitófagos associadas à cultura do morangueiro e seus inimigos naturais, os principais métodos de controle, e propor técnicas de manejo que possam ser adequadas ao sistema de produção integrada da cultura.

\section{Ácaros-praga do morangueiro}

Os ácaros são considerados pragas primárias da cultura do morangueiro. O controle destas pragas por métodos químicos é dificultado pelo fato de as colheitas do morangueiro serem realizadas diariamente e o fruto consumido in natura, daí a necessidade de aplicarem-se acaricidas com pequeno período de carência e com baixa toxidade. As injúrias causadas na planta pelos ácaros são provocadas pela perfuração das células da epiderme inferior das folhas, podendo também atacar os frutos quando estes estão verdes. Os ácaros alimentam-se do conteúdo intracelular das folhas, causando a morte das células atacadas e, em conseqüência, provocam o aparecimento de manchas ou áreas descoradas. Em altas densidades, os ácaros podem reduzir a taxa fotossintética das plantas do morangueiro por causarem danos às células do mesófilo foliar e o fechamento dos estômatos, acarretando redução no número e no peso dos frutos.

\section{Ácaro-rajado}

Tetranychus urticae Koch, 1836 (Acari: Tetranychidae)

O ácaro-rajado é a principal praga da cultura do morangueiro, podendo reduzir a produção de frutos em até $80 \%$, no ponto máximo de desenvolvimento da população, quando não controlado ou controlado de forma incorreta (CHIAVEGATO \& MISCHAN, 1981). Esta espécie é polífaga e cosmopolita, atacando, além do morangueiro, outras culturas, como o tomateiro, feijoeiro, soja, pessegueiro, figueira, etc. Os machos medem aproximadamente $0,25 \mathrm{~mm}$ e diferem morfologicamente das fêmeas que medem aproximadamente $0,46 \mathrm{~mm}$ de comprimento. A forma adulta da fêmea apresenta o dorso de coloração amarelo-esverdeada escura, coberto por longas setas e possui duas manchas escuras em cada lado. Após a colonização da planta do morangueiro, o ácaro-rajado tece, na face inferior das folhas, um entrelaçado de fios de seda que, posteriormente, apresenta característica de uma teia. Sobre esta teia, a fêmea realiza a oviposição, podendo, também, depositar os ovos diretamente sobre a superfície foliar. Os ovos são de coloração amarelada, esféricos e de difícil visualização a olho nu. A fase jovem do ácaro é semelhante à fase adulta, diferindo apenas pelo tamanho. Apresenta três pares de pernas na fase de larva e quatro nas fases de ninfa e adulto (FLECHTMANN, 1985).

As injúrias causadas são conseqüência da alimentação do ácaro que rompe, com suas quelíceras, as células da epiderme inferior das folhas do morangueiro. As folhas atacadas adquirem manchas difusas de coloração avermelhada no início e, posteriormente, secam e caem (NAKANO et al., 1992). À semelhança do que ocorre em outras culturas, temperaturas elevadas e baixas precipitações podem levar ao aumento populacional desta praga.

\section{Ácaro-do-enfezamento}

Steneotarsonemus pallidus (Banks, 1898) (Acari: Tarsonemidae)

Esta espécie é de difícil visualização, mede cerca de $0,3 \mathrm{~cm}$ de comprimento. As fêmeas apresentam coloração de castanho-clara a laranjarosada ou ainda branca e brilhante. Os machos possuem coloração amarelada e são menores que as fêmeas. O ciclo de vida dura de 10 a 30 dias. Esta espécie evita luz do sol e abriga-se na parte central da planta, nas folhas não abertas entre os pecíolos, na base das pétalas, na face interna das sépalas e na pilosidade dos frutos imaturos. Em pequenas 
infestações, nota-se enrugamento na face superior das folhas, as quais se apresentam aglomeradas. Quando as infestações são severas, ocorre encarquilhamento na região da coroa. As folhas mais novas não se abrem completamente, ficam pequenas e com os pecíolos bastante curtos, tornando-se amarelecidas a bronzeadas e endurecidas. As flores e os frutos tornamse bronzeados na base, podendo secar e cair. Os frutos ainda podem ter o seu tamanho reduzido (PALLINI et al., 2002).

\section{Ácaro-vermelho}

Tetranychus desertorum Banks,1900 (Acari: Tetranychidae)

O ácaro-vermelho produz injúrias semelhantes às do ácaro-rajado. Atacam as folhas que adquirem manchas difusas de coloração avermelhada no início e, posteriormente, secam e caem, podendo reduzir o tamanho e número de frutos. As fêmeas adultas dessa espécie possuem coloração avermelhada, enquanto os machos e formas imaturas apresentam coloração verde-amarelada (FLECHTMANN, 1985).

\section{Sistema de amostragem}

O monitoramento da população de ácaros no campo deve ser periódico. $\mathrm{O}$ agricultor deve saber identificar as principais espécies de pragas e seus inimigos naturais para que a contagem dos indivíduos seja precisa. No caso do morangueiro, a amostragem consiste na coleta de folhas, flores e frutos verdes, que podem ser acondicionados em sacos de papel e armazenados em geladeira por até três dias. A contagem é realizada com auxílio de lupa específica para contagem de ácaros com aumento de vinte vezes. Para o ácaro-rajado, o número de indivíduos capaz de causar dano econômico ao morangueiro varia de 20 a 100 ácaros por área de contagem em lupas $\left(4 \mathrm{~cm}^{2}\right)$ (RAWORTH, 1986).

O intervalo entre amostragens ou freqüência de amostragem é determinado em função do período de geração da espécie de ácaro-praga amostrada, da fenologia da planta, das condições climáticas e da ocorrência da praga. Em períodos de maior ocorrência da praga aconselha-se aumentar a freqüência de amostragem. Outro fator a ser considerado em programas de amostragem de ácaros é a distribuição da população no habitat. Em populações onde os indivíduos se encontram distribuídos homogeneamente, o número e tamanho das amostras podem ser menores do que naquelas onde os indivíduos estão agregados, sem alterar, contudo, o grau de eficiência da amostragem. A distribuição de ácaros em uma planta é mais homogênea do que entre plantas, isto devido, principalmente, à baixa capacidade de dispersão dos ácaros. Desta forma, para que se consiga uma amostragem representativa da população deve-se amostrar um maior número de plantas em detrimento do número de observações por planta.

\section{Medidas de controle}

Nos sistemas de produção integrada, o uso de acaricidas é restrito e deve obedecer às normas de cada procedimento (FRÁGUAS et al., 2001), sendo indicados pesticidas seletivos, com baixa persistência, específicos e que não deixem resíduos nos frutos.

SUCKLING et al. (1999) compararam o impacto de três sistemas de manejo de pragas em pomares de maçã: convencional, integrado e biológico. No sistema convencional, utilizaram-se inseticidas e acaricidas de largo espectro, atendendo às necessidades quarentenárias de mercados externos. No sistema integrado, utilizaram-se o mínimo de aplicações necessárias e produtos com ação seletiva. No sistema biológico, de controle de praga utilizaramse feromônio sexual para alterar o comportamento de acasalamento, controle microbiano com Bacillus thuringiensis e cobertura vegetal nas entrelinhas dos pomares para manter populações de inimigos naturais. Nos três sistemas de manejo, o ácaro predador Typhlodromus pyri (Phytoseiidae) estava presente mesmo no sistema convencional apesar das aplicações de organofosforados. O predador de ácaros Galendromus occidentalis (Phytoseiidae) também foi encontrado nos três sistemas de manejo.

Os sistemas de produção convencionais possuem alta eficiência técnica no controle fitossanitário, ou seja, baixos níveis populacionais de pragas e frutos de boa aparência. Contudo, em detrimento às exigências do mercado consumidor, problemas com o surgimento de populações de pragas resistentes e frutos com alta concentração de resíduos são freqüentes. Estudos comparativos, que avaliem a eficiência de controle de ácaros na cultura do morangueiro e sua conseqüência ao consumidor e meio ambiente, em diferentes sistemas de manejo, são necessários, contudo, ainda inexistentes.

\section{Controle químico}

BRANZANTI (1989) recomenda que o controle de ácaros, para ser eficaz, deve ser realizado rapidamente, assim que os primeiros sintomas de ataque sejam observados e o nível de controle alcançado. O controle químico de ácaros para a cultura do morangueiro é dificultado pelo reduzido número de acaricidas registrados para a cultura. Assim, a utilização de acaricidas deve ser criteriosa para que a 
qualidade do produto e a segurança do consumidor e do aplicador sejam garantidas. Observações de campo têm mostrado que o controle é mais eficaz quando a aplicação do produto é feita utilizando pulverizadores motorizados, ao contrário das manuais. Isto ocorre, provavelmente, pela maior penetração do produto na região da coroa da planta, onde os ácaros se encontram mais protegidos.

O surgimento de populações resistentes aos acaricidas é outro fator limitante ao uso de pesticidas (SATO et al., 1994). A resistência aos acaricidas é comum e pode ser rapidamente desenvolvida pelas populações segundo GOULD (1973), e pode ser definida como a redução da sensibilidade de determinada população a um acaricida. A desintoxicação natural, a absorção mais lenta da toxina e a fuga de sítios de perigo (=resistência comportamental) são alguns mecanismos de resistência utilizados pelos ácaros para evitar ação deletéria de acaricidas (PAVAN, 2002). A estratégia fundamental para evitar-se o surgimento de populações resistentes é reduzir a pressão de seleção dos acaricidas sobre os ácaros. Isto pode ser alcançado utilizando o manejo integrado de pragas, conforme cita PEDIGO (1999).

\section{Controle biológico}

No controle biológico aplicado, predadores, parasitóides e patógenos, nativos ou exóticos, são multiplicados no laboratório e liberados no campo para controlar as pragas alvo. As liberações dos inimigos naturais criados massalmente podem ser de forma inundativa, quando os inimigos naturais são liberados em grande número visando um controle imediato, ou de forma inoculativa, quando os inimigos naturais são liberados também em grande número mas visando além do controle imediato, a formação de uma população de inimigos naturais capaz de controlar as gerações das pragas durante o período da cultura. Para que o sucesso do controle biológico seja completo, é necessário, entre outros, que os inimigos naturais liberados encontrem condições de se manterem e se multiplicarem (VENZON et al., 2003).

O controle biológico de ácaros fitófagos na cultura do morangueiro ainda é incipiente e pouco utilizado no Brasil (WATANABE et al., 1994). Contudo, se implementado, poderia representar um importante passo para a redução do uso de acaricidas. O controle biológico através de liberações de ácaros predadores da família Phytoseiidae tem apresentado resultados promissores em países da América do Norte e Europa (EASTERBROOK et al., 2001).
O controle biológico deve estar associado a um plano de manejo cultural, ou seja, sistema de cultivo convencional, que utiliza pesticidas em larga escala, é candidato ao fracasso no uso de controle biológico (FADINI \& ALVARENGA, 1999). Em sistemas como o de produção integrada ou o orgânico, os quais utilizam menos ou nenhum pesticida, existem maiores chances de implementar com sucesso o controle biológico de ácaros na cultura do morangueiro.

MORAES (1991) cita que os ácaros predadores são os inimigos naturais mais eficientes no controle dos ácaros fitófagos. Algumas famílias de ácaros predadores, como Anystidae, Bdellidae, Cheyletidae, Tydeidae e Stigmaeidae, podem realizar o controle de ácaros fitófagos; contudo, a família Phytoseiidae destaca-se como a mais importante (WATANABE et al., 1994; EASTERBROOK et al., 2001). No Brasil, várias espécies de predadores fitoseiídeos são encontradas em várias culturas com grande potencial de serem exploradas (e.g. Iphiseiodes zuluagai, Euseius concordis e Euseius hibiscus) (PALLINI et al., 1992).

Além dos ácaros predadores [Phytoseiulus macropilis, Phytoseiulus persimilis, Amblyseius californicus, Galendromus (=Metaseiulus) occidentalis], outros agentes de controle biológico, como joaninhas (Stethorus spp), tripes (Scolothrips ssp) e percevejos predadores (Orius ssp), são utilizados em programas de controle biológico na Europa e Estados Unidos (FRESCATA \& MEXIA, 1996; GARCIA-MARI \& GONZALEZ-ZAMORA, 1999; CROSS et al., 2001).

O controle biológico conservativo é uma estratégia utilizada para promover a sobrevivência e o desempenho comportamental e fisiológico de inimigos naturais já existentes no campo (BARBOSA, 1998). Essa técnica consiste no fornecimento de condições ambientais ideais para os inimigos naturais para que eles possam regular as populações de pragas, mantendo-as abaixo dos níveis de dano econômicos. A manutenção de populações de inimigos naturais no campo é fundamental para o controle de ácaros. Para tanto, devem-se fornecer condições e recursos suficientes para tais populações no campo. $\mathrm{O}$ aumento da diversidade vegetal, através de culturas intercalares e espécies companheiras, parece ser uma técnica promissora para tal propósito (LAMONDIA et al., 2002), como é o caso de culturas como a videira (FADINI et al., 2001), batata, couve e berinjela (VENZON et al., 2001).

Os fungos agentes de controle microbiano Hirsutella thompsonii, Hirsutella nodulosa e 
Verticillium lecanii são apontados como mais promissores no controle de ácaros fitófagos (PALLINI, et al. 2002). Tais agentes de controle, apesar de não serem utilizados em larga escala, devem ser preservados.

\section{Controle cultural}

O controle cultural de ácaros consiste em tornar as condições do ambiente menos favoráveis para as populações de fitófagos, reduzindo seu potencial reprodutivo e aumentando a taxa de mortalidade e favorecer populações de inimigos naturais. Como técnicas de controle cultural de ácaros em morangueiro, poder-se-iam explorar as defesas constitutivas e induzidas das plantas à herbivoria, ao uso de bordaduras e à aquisição de mudas certificadas.

As defesas das plantas contra herbívoros podem ser divididas em constitutivas e induzidas segundo KARBAN \& BALDWIN (1997). As defesas constitutivas estão presentes nas plantas e não dependem da presença dos herbívoros para serem expressadas. Um exemplo de defesas constitutivas é relatado por LOURENÇÃO et al. (2000), que avaliou a resistência de 14 cultivares de morangueiro, uma linhagem (T-0104) e outras três cultivares de morangueiro com diferentes graus de resistência ao ácaro-rajado. Dentre os clones avaliados, os menores sintomas de ataque foram observados na linhagem T0104 e nas cultivares Blakemore, Raritan e IAC Princesa Isabel em comparação com as cultivares Cruz e Oso Grande. Contudo, não foi identificada preferência em oviposição entre os materiais testados, considerando-se, entretanto, a atratividade e preferência em laboratório, pode-se recomendar o uso das cultivares IAC Princesa Isabel, IAC Campinas e New Jersey 73335-5, por apresentarem comportamento de resistência ao ácaro-rajado.

KARBAN (1999) cita que plantas de morangueiro, quando pulverizadas com ácido jasmônico, são capazes de produzir voláteis que atraem ácaros predadores, que, por sua vez, têm o potencial de reduzir populações de ácaros fitófagos. Outra alternativa para tentar-se reduzir aplicações de pesticidas é a integração de técnicas culturais, como bordaduras e eliminação de restos de cultura, aos métodos convencionais de controle. As bordaduras são espaços livres entre os canteiros e outras culturas com largura de 3 a $5 \mathrm{~m}$, que servem como barreira física entre a cultura e as possíveis fontes de ácaros das adjacências. Como os ácaros são ápteros e de tamanho reduzido, uma faixa, como na largura citada, torna-se um obstáculo de difícil transposição, embora o vento seja um dos principais meios de disseminação dos ácaros. RONQUE (1998) aconselha também, realizar pulverizações, nestas áreas, com acaricidas para dificultar o acesso da praga à cultura.

A qualidade das mudas adquiridas também é fator importante no manejo de ácaros do morangueiro, pois elas são as principais disseminadoras de pragas e doenças da cultura (FACHINELLO, 1999). Mudas que possuam menor quantidade de ovos e adultos de ácaros produzirão lavouras com menores infestações.

Além das práticas mencionadas, RONQUE (1999) recomenda-se que, a rotação de culturas, a eliminação de plantas hospedeiras, a eliminação de plantas com ataque dentro da lavoura e a não-irrigação por aspersão após a aplicação de acaricidas podem auxiliar na redução das populações de ácaros fitófagos.

\section{CONSIDERAÇÕES FINAIS}

Para adequar o atual sistema de produção de morango ao de produção integrada, será necessário reduzir o impacto dos pesticidas na cultura. Com este propósito, o uso acaricidas seletivos, o uso de controle biológico com predadores, o uso de técnicas como a indução de respostas diretas e indiretas de plantas ao ataque ácaros, além da conscientização de consumidores e de produtores, podem ser técnicas promissoras para reduzir os riscos de contaminação do meio ambiente e dos frutos por pesticidas. O manejo fitossanitário e todas as práticas culturais (e.g. adubação, espaçamento, qualidade das mudas, variedades, controle cultural, restos de cultura etc.) devem ser considerados.

\section{AGRADECIMENTO}

À Fundação de Amparo a Pesquisa do Estado de Minas Gerais (FAPEMIG). Este artigo foi produzido a partir das discussões da disciplina Acarologia Agrícola - UFV - (BAN$678)$.

\section{REFERÊNCIAS BIBLIOGRÁFICAS}

ANTUNES, L.E.C; FADINI, M.A.M. Caracterização frutícola em Minas Gerais: situação e perspectivas da produção integrada de frutas. Informe Agropecuário, v.22, n.213, p.72-74, 2001.

BARBOSA, P. Conservation biological control. San Diego : Academic, 1998.

BRASIL. Ministério da Agricultura, Pecuária e Abastecimento. Instrução Normativa n. 7, de maio de 1999. Dispõe sobre normas para a produção de produtos orgânicos vegetais e animais. LEX - coletânea de Legislação e Jurisprudência: legislação federal e marginalia, v.63, n.5, p.2465-2476, 1999. 
BRASIL. Ministério da Agricultura, Pecuária e Abastecimento. Instrução Normativa n. 20, de 27 de fevereiro de 2001. Diário Oficial da República Federativa do Brasil, v.1, p.40-44, 2001.

CHIAVEGATO, L.G.; MISCHAN, M.M. Efeito do Tetranychus (T.) urticae (Koch, 1836) Boudreaux \& Dosse, 1963 (Acari, Tetranychidae) na produção do morangueiro (Fragaria $\mathrm{sp}$ ) cv. 'Campinas'. Científica, v.9, n.2, p.257-266, 1981.

CROSS J.V. et al. Natural enemies and biocontrol of pests of strawberry in northern and central Europe. Biocontrol Science and Technology, v.11, n.2, p.165-216, 2001.

EASTERBROOK, M.A.; FITZGERALD J.D.; SOLOMON, M.G. Biological control of strawberry tarsonemid mite Phytonemus pallidus and two-spotted spider mite Tetranychus urticae on strawberry in the UK using species of Neoseiulus (Amblyseius) (Acari : Phytoseiidae). Experimental and Applied Acarology, v.25, n.1, p.25-36, 2001 .

FACHINELlO, J.C. Produção de mudas certificadas de morangueiro na Itália. In: DUARTE FILHO, J. et al. Morango tecnologia de produção e processamento. Caldas : EPAMIG, 1999. p.73-92.

FACHINELLO, J.C. Produção integrada de frutas: um breve histórico. Informe Agropecuário, v.22, n.213, p.15-18, 2001.

FADINI, M.A.M.; ALVARENGA, D. Pragas do morangueiro. Informe Agropecuário, v.20, n.198, p.75-79, 1999.

FADINI, M.A.M.; LOUZADA, J.C.N. Impactos ambientais da agricultura convencional. Informe Agropecuário, v.22, n.213, p.24-29, 2001.

FADINI, M.A.M. et al. Efeito da cobertura vegetal do solo sobre a abudância e diversidade de inimigos naturais de pragas em vinhedos. Revista Brasileira de Fruticultura, v.23, n.3, p.573576, 2001.

FLECHTMANN, C.H.W. Ácaros de importância agrícola. São Paulo : Nobel, 1985.

FRÁGUAS, J.C.; FADINI, M.A.M.; SANHUEZA, R.M.V. Componentes básicos para elaboração de um programa de produção integrada de frutas. Informe Agropecuário, v.22, n.213, p.19-23, 2001.

FRESCATA, C.; MEXIA A. Biological control of thrips (Thysanoptera) by Orius laevigatus (Heteroptera: Anthocoridae) in organically-grown strawberries. Biological Agriculture and Horticulture, v.13, p.141-148, 1996.

GARCIA-MARI, F.; GONZALEZ-ZAMORA, J.E. Biological control of Tetranychus urticae (Acari: Tetranychidae) with naturally occurring predators in strawberry plantings in Valenica, Spain. Experimental and Applied Acarology, v.23, n.6, p.487495, 1999.

GOULD, H.J. Laboratory and field investigations with organophosphorus resistant Tetranychus urticae on strawberries. Annual Applied Biology, v.74, p.17-23, 1973.

HELLE, W.; SABELIS, M.W. Spider mites: their biology, natural enemies and control. Amsterdam: Elsevier, 1985. $1 \mathrm{~A} \mathrm{v}$.
KARBAN, R. Future use of plant signals in agricultural and industrial crops. Novartis Foudantion Symposium 223, p.223238, 1999.

KARBAN, R.; BALDWIN, I.T. Induce responses to herbivory. Chicago, The University of Chicago, 1997.

LAMONDIA, J.A. et al. Integrated management of strawberry pests by rotation and intercropping. Crop Protection, v.21, p.837846, 2002.

LOURENÇÃO, A.L. et al. Resistência de morangueiro a Tetranychus urticae Kock (Acari: Tetranychidae). Anais da Sociedade Entomológica do Brasil, v.29, n.2, p.339-346, 2000.

MORAES, G.J. Controle biológico de ácaros fitófagos. Informe Agropecuário, v.15, n.167, p.53-55, 1991.

NAKANO, O.; PARRA, J.R.P.; MARCHINI, L.C. Pragas das hortaliças e ornamentais. In: FEALQ. Curso de Entomologia aplicada a agricultura. Piracicaba : FEALQ, 1992. p.441-476.

PALLINI, A. et al. Manejo integrado de ácaros em fruteiras tropicais e subtropicais. In.: ZAMBOLIM, L. Manejo integrado de fruteiras tropicais doenças e pragas. Viçosa : Universidade Federal de Viçosa, 2002. p.579-614.

PALLINI, A.; MORAES, G.J.; BUENO, V.H.P. Ácaros associados ao cafeeiro Coffea arabica L. no sul de Minas Gerais. Ciência e Prática, v.13, p.123-130, 1992.

PAVAN, L.A. Resistencia de insetos a inseticidas. In: ZAMBOLIM, L. Manejo integrado de fruteiras tropicais doenças e pragas. Viçosa : Universidade Federal de Viçosa, 2002. p.651-671.

PEDIGO, L.P. Entomology and pest management. 3.ed. Prentice-Hall : Englewood Cliffs, 1999.

PESSOA, M.C.PY; SILVA, A.S.; CAMARGO, C.P. Qualidade e certificação de produtos agrícolas. Brasília : Embrapa, 2002. 188p. (Texto para Discussão, 14).

RAWORTH, D.A. An economic threshold function for the twospotted spider mite, Tetranychus urticae (Acari: Tetranychidae), on strawberries. The Canadian Entomologyst, v.118, p.9-16, 1986.

RONQUE, E.R.V. Cultura do morangueiro revisão e prática. Londrina : EMATER, 1998.

RONQUE, E.R.V. Principais pragas da cultura do morangueiro. In: DUARTE FILHO, J. et al. Morango - tecnologia de produção e processamento. Caldas : EPAMIG, 1999. p.51-64.

SATO, M.E. et al. Resistência do ácaro rajado Tetranychus urticae (Koch, 1836) (Acari: Tetranychidae) a diversos acaricidas em morangueiro (Fragaria sp.) nos municípios de Atibaia-SP e Piedade-SP. Ecossistema, v.19, p.40-46, 1994.

SUCKLING, D.M.; WALKER, J.T.S.; WEARING, C.H. Ecological impact of three pest management systems in New Zealand apple orchards. Agriculture, Ecossystems and Environment, v.73, p.129-140, 1999.

TITI, A. EL; BOLLER, E.F.; GENDRIER, J.P. Producción integrada: principios y directrices técnicas. IOBC/WPRS, 1995. 22p. (Boletim Técnico, 8). 
VENZON, M.; PALLINI, A.; AMARAL, D.S.S.L. Estratégias para o manejo ecológico de pragas. Informe Agropecuário, v.22, n.212, p.19-28. 2001

VENZON, M.; FADINI, M.A.M.; ROSADO, M.C. Controle biológico de pragas de fruteiras. In: ZAMBOLIM, L. Produção integrada de fruteiras tropicais - Manejo integrado de doen- ças e pragas. Viçosa : Suprema Gráfica e Editora, 2003. p. 223 242.

WATANABE, M.A. et al. Controle biológico do ácaro rajado com ácaros predadores fitoseídeos (Acari: Tetranychidae, Phytoseiidae) em cultura de pepino e morango. Scientia Agricola, v.51, n.1, p.75-81, 1994.

Ciência Rural, v. 34, n.4, jul-ago, 2004. 